\title{
Ageing drivers' mental workload in real-time driving tasks based on subjective and objective measures
}

\author{
Nurul Izzah Abd Rahman*, Siti Zawiah Md Dawal** and Nukman Yusoff** \\ *Department of Mechanical and Manufacturing Engineering, Faculty of Engineering, Universiti Putra Malaysia, 43400 Serdang, Selangor, Malaysia. \\ **Department of Mechanical Engineering, Faculty of Engineering, University of Malaya, 50603 Kuala Lumpur, Malaysia. \\ *Corresponding Author: izzahrahman@upm.edu.my
}

Submitted: 08/12/2019

Revised: $\quad 09 / 01 / 2021$

Accepted: 09/02/2021

\begin{abstract}
The ageing drivers' population is increasing rapidly, and they are exposed to disabilities due to degenerative processes, thus affecting their driving performance. The main objective of this study is to determine the mental workload of ageing drivers, while the second objective is to compare the mental workload between ageing drivers and control group. The methodology consisted of on-the-road experimental driving tasks that comprised three levels of situation complexity. The NASA-Task Load Index (NASA-TLX) and electroencephalogram (EEG) were measured on 30 drivers. The NASA-TLX scores revealed that the ageing drivers' mean physical demand score was the highest compared to others in moderately complex situation and very complex situation, scoring 37.25 and 43.50 , respectively. Meanwhile, for electroencephalogram signals' fluctuation, results showed that situation complexity had significant effects on RP $\theta$ and RP $\alpha$ of channel locations FZPZ and O1O2. There was a significant difference in the weighted workload scores for the ageing drivers and control group in simple situation, while there was no significant difference found in RP $\theta$ and $\mathrm{RP} \alpha$ bands at all channel locations. The findings would be beneficial as a guideline for designers, manufacturers, developers, and policy makers in designing better driving environment for ageing drivers.
\end{abstract}

Keywords: Ageing drivers; Mental workload; NASA-TLX; Electroencephalogram.

\section{INTRODUCTION}

People around the world are living longer (World Health Organization, 2018). Most countries nowadays have a large portion of ageing population, and this number is increasing dramatically. In 2015, there were more than $52 \%$ people aged 50 and above worldwide compared to the year 2000 . By 2100 , the number of older people is projected to have more than tripled (United Nations Department of Economic and Social Affairs, 2014). As one of developing countries in the world, Malaysia's ageing population is growing. In Malaysia, declining fertility has imposed direct and indirect implications over older people and their family members. They are likely to be affected by the consequent demographic changes and other activities in the Malaysian society and economy (Arokiasamy, 1999). It is consequential that a growing number of older individuals will continue to become active drivers (Böcker et al., 2017; Cheung \& McCartt, 2011).

Attributed to the development and advancement of mechanization and automation, mental workload is one of the important concerns in transportation systems. Mental workload can be simply pictured as the relationship of mental capacity and the task on demand. As long as there is an activity involved in one's condition, a task demand occurs in accomplishing the goal of the task. Mental workload can be simplified as the relationship between the mental demand of a task and the worker's being (Leung, 2006; De Waard, 1996). Even though the term 'mental workload' will directly give the idea of just mental resources, physical capacity also contributes to mental workload. Both cannot be fully separated when a subject is performing a task (Fallahi et al., 2016; Lean \& Shan, 2012). 
Previously, researchers were inspired to study mental workload after realizing the importance of this human factor. Three types of measurements have generally been used to measure mental workload particularly for drivers, namely, subjective measures, physiological measures, and performance measures of driving tasks (Lei \& Roetting, 2011; HQs Civil Aviation Authority, 2009; Hwang et al., 2007; Ryu \& Myung, 2005). Self-reported measurements, usually known as subjective measures, are one of the reliable methods used by previous studies on mental workload. There are questionnaires usually used in driving study, e.g., Subjective Workload Assessment Technique (SWAT; (Reid \& Nygren, 1988)); workload profile (WP; (Tsang \& Velazquez, 1996)); and National Aeronautics and Space Administration task load index (NASA-TLX; (Hart \& Staveland, 1988)). The NASA-TLX has more technical advantages compared to the others (i.e., dimensions, task performance predictions, applicability on real complex tasks, sensitivity, diagnosticity, selectivity/validity, and intrusiveness) (Paxion et al., 2014).

Another method that has been extremely effective in the evaluation of mental workload is physiological measurements (Lei \& Roetting, 2011; Hwang et al., 2007; Ryu \& Myung, 2005). Among the most widely used physiological parameters by experts are brain signal activity measurements using EEG, heart rate, eye blinking, and heart rate variability. Among these advanced measurements, EEG tool is more acceptable and accurate in providing a quantitative measurement of human performance (Ryu \& Myung, 2005; Chen \& Vertegaal, 2004).

This paper focuses on two types of mental workload measurements, which are the subjective and physiological measures to fulfil the objectives, namely, (1) to determine the mental workload of ageing drivers in real-time driving task, and (2) to compare between the mental workload of the ageing drivers and the control group. It is important that the findings from this study are to be used by designers, manufacturers, developers, and policy makers in structuring better driving conditions for ageing drivers.

\section{METHODOLOGY}

\section{(1) Participants}

In this study, 30 healthy drivers were recruited through poster advertisements and social media. Ten of the total participants were young drivers assigned to the control group, purposely as comparison for each measure. The numbers of each gender were equal. To qualify as participants, volunteers had to fulfil the requirements of holding a driver's license for at least 5 years and having driven for at least 10,000 km during the last year. They were informed of the study's goal, methodology, and potential hazards in verbal and writing to which they all acknowledged afterwards. Participants received a token of appreciation for their participation.

\section{(2) Experimental driving environment}

The routes were identical to all participants, because they needed to drive through them, making the total distance of driving tasks as approximately $27 \mathrm{~km}$, which took an average of about 30 to 45 minutes. To ensure the participants maintain their own driving style, the experiments were conducted at off-peak period (weekdays only), i.e., 9 in the morning to 12 noon before lunch hour (Son et al., 2015). Table 1 shows the details of routes and environments.

Table 1. The route settings.

\begin{tabular}{llll}
\hline Descriptions & $\begin{array}{l}\text { A: Simple situation } \\
\text { (SS) }\end{array}$ & $\begin{array}{l}\text { B: Moderately complex } \\
\text { situation (MCS) }\end{array}$ & $\begin{array}{l}\text { C: Very complex } \\
\text { situation (VCS) }\end{array}$ \\
\hline Road design & Highway & Rural Road & City Road \\
Speed limits & $110 \mathrm{~km} / \mathrm{h}$ & $90 \mathrm{~km} / \mathrm{h}$ & $60 \mathrm{~km} / \mathrm{h}$ \\
Road layout & Straight & Few curves & Many curves \\
Traffic flow & Low density & Moderate density & High density \\
Light condition & Daytime & Daytime & Daytime \\
Weather condition & No rain & No rain & No rain \\
\hline
\end{tabular}




\section{(3) Experimental setup and measures}

An instrumented experimental sedan car was used during the driving tasks. In this car, two cameras, computer devices, and EEG set were installed. Two cameras recorded forward driving scenes. The environment during the driving task and driver's behavior was recorded and synchronized with the EEG data. NASA-TLX (Hart \& Staveland, 1988) was used to evaluate the operator's subjective workload. The participants were asked to self-report their mental workload after finishing every primary task of each route session. Each participant was expected to take approximately 5 to 10 minutes to complete the subjective assessment. The NASA-TLX method includes six subscales (mental demand, physical demand, temporal demand, performance, effort, frustration level) and the source of workload comparison cards. The mean (raw TLX) and weighted mean (weighted workload) were calculated using paired comparisons. To ensure scores taken from the two groups can be compared and to avoid different perceptions on the scales, systematic approaches were executed. An extremely clear explanation was made on NASA-TLX to participants regardless of the type of group before starting the experiment. An example was shown on how to answer the tools to ensure their understanding. Each participant was allowed to ask if there were further questions regarding the tool while making a rating in the experimental session. The participants were fitted with a stretch $\mathrm{AgCl}$ electrodecap (MP150 System and BIOPAC EEG100C) (Figure 1). These electrodes were pre-positioned with the basis of the study, and were placed at $\mathrm{F}_{\mathrm{Z}}, \mathrm{P}_{\mathrm{Z}}, \mathrm{O}_{1}, \mathrm{O}_{2}, \mathrm{P}_{3}$, and $\mathrm{P}_{4}$ of the International 10/20 montage (Andreassi, 2000), with an electronically linked ear lobe reference. Thereafter, electrooculogram (EOG) recording was done by using electrodes placed above and below each eye, and parallel with jumper leads when connecting to the vertical track of EOG module to increase accuracy. The EOG signals served to identify and remove blink artefacts.

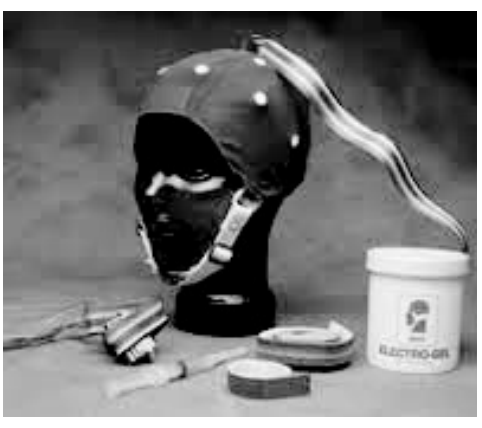

a)

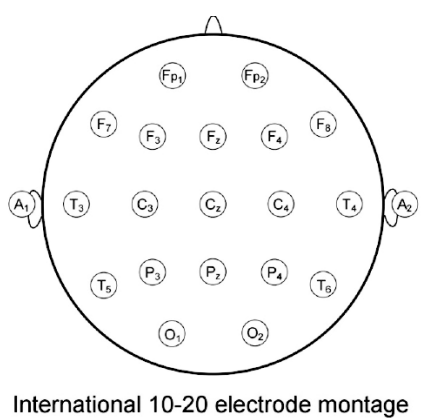

b)

Fig. 1. The a) $\mathrm{AgCl}$ electrode-cap of MP150 System and b) electrodes placements.

The signals processing was done using Acq-Knowledge 4.0 software (BIOPAC Systems Inc.) filtered between 1 and $100 \mathrm{~Hz}$, and digitally recorded (1000 Hz sample frequency) as a step to estimate Power Spectral Density (PSD). EEGs were corrected for vertical and horizontal eye movements based on EOG signals, which is the method of Zadry et al. (2011, 2010). Fast Fourier Transform (FFT) was then performed on the selected data for every $2 \mathrm{~s}$ segment and the PSD data (unit: $\mu \mathrm{v}^{2}$ ) was obtained. The spectral power was calculated for the two crucial EEG bands of the study: theta (4-7.99 Hz), alpha (8-12.99 Hz). In addition, a Matlab program (MATLAB R2010a, MathWorks, Natick, Massachusetts) was written to estimate the PSD of the EEG signals for each subject. Then, the output was normalized to achieve the theta, alpha, and beta relative power (i.e., RP $\theta, R P \alpha$, and $R P \beta$ ) using the following equations, respectively (Doufesh et al., 2014; Amodio et al., 2009):

$$
R P \theta=\frac{\int_{f l}^{f h} S x(f) d f}{\int_{0}^{f m a x} S x(f) d f} \times 100
$$

where $\operatorname{fmax}=95 \mathrm{~Hz}, f l=4 \mathrm{~Hz}, f h=7.99 \mathrm{~Hz}$; 
$R P \alpha=\frac{\int_{f l}^{f h} S x(f) d f}{\int_{0}^{f \max } S x(f) d f} \times 100$

where $\max =95 \mathrm{~Hz}, f=8 \mathrm{~Hz}, f h=12.99 \mathrm{~Hz}$;

\section{(4) Experimental procedure}

The experimental procedure was approved by the UM Research Ethics Committee (UMREC). In this study, participants were individually briefed on the experiment details upon their arrival at the setup station. Once they understood all the details, the participants signed an informed consent and filled out a demographic questionnaire. Thereafter, they were all given the chance to familiarize themselves with the vehicle and environment by driving around on a two-lane practice road without any traffic. Also, it was emphasized to the participants that their priority was to drive safely. Subsequently, they were notified to drive according to the route that had been set. To achieve accurate measures, the researcher was seated at the back to monitor the measuring equipment and a research associate was seated beside the driver to give driving directions while ensuring safe vehicle operations. At the end of each simple, moderately complex, and very complex situation session, participants were directed to pull over and park the car for a break and complete the subjective ratings based on that session. A strategy to randomize the order of the sessions was implemented to minimize bias due to carryover effect. It was expected that the order effect due to the sequence of three roadway types would be relatively small as driving tasks were kept under control (Son et al., 2015).

\section{(5) Data Analysis}

The analysis of the study was done based on the objectives, which was carried out using the IBM Statistical Package for Social Science (SPSS) for Windows version 23.0 (Armonk, NY: IBM Corp). Prior to data analysis, all variables were subjected to normality test using skewness and kurtosis. With regards to fulfilling the first objective, the mixed model repeated measures ANOVA was used to analyze the mental workload (NASA-TLX and EEG relative power bands) measures' outcomes of ageing drivers in varying degrees of situation complexity. Next, comparisons were made between the age groups using T-test to investigate the differences. For the EEG output, the raw data was acquired from Acq-Knowledge 4.0 software (BIOPAC Systems Inc.), processed and normalized into the relative power bands. The mixed model repeated measures ANOVA consists of repeated measures of between-subjects factor (two levels: male and female), situation complexity (three levels: simple situation, moderately complex situation, and very complex situation), and time on task (ToT) (three levels: subminutes 1 (S1) to subminutes 3 (S3)) as within-subjects factors for EEG frequency bands.

\section{RESULTS}

The mean age of male ageing participants was $57.6(\mathrm{SD}=2.32)$ with a mean driving experience of 34.40 years $(\mathrm{SD}=4.77)$. Meanwhile, the mean age of female ageing participants was $58.00(\mathrm{SD}=3.16)$ with a mean driving experience of 24.80 years $(\mathrm{SD}=8.90)$. On the other hand, the mean age of male control participants was 28.00 (SD $=3.08)$ with a mean driving experience of 8.80 years $(\mathrm{SD}=3.70)$, while the mean age of female control participants was $27.60(\mathrm{SD}=2.30)$ with a mean driving experience of 8.60 years $(\mathrm{SD}=3.65)$.

\section{(1) Subjective ratings on different situation complexity}

Table 2 and Figure 2 present the mean and standard deviation. The mean PD score obtained was the highest compared to others in rural and city driving for the ageing drivers. Additionally. the results also indicated that the physical demand more than doubled as the driving situation shifted from simple situation to moderately complex and very complex situations. Furthermore, the overall weighted workload (WWL) exhibited the highest score on city roads followed by rural roads. 
Table 2. Descriptive Statistics for NASA-TLX scales for simple situation, moderately complex situation, and very complex situation.

\begin{tabular}{|c|c|c|c|c|c|c|c|}
\hline \multirow{2}{*}{ Scale } & \multirow{2}{*}{$\mathbf{N}$} & \multicolumn{2}{|c|}{ SS } & \multicolumn{2}{|c|}{ MCS } & \multicolumn{2}{|c|}{ VCS } \\
\hline & & Mean & SD & Mean & SD & Mean & SD \\
\hline MD & 20 & 19.64 & 13.19 & 28.69 & 18.11 & 38.50 & 22.60 \\
\hline PD & 20 & 15.39 & 5.86 & 37.25 & 26.33 & 43.50 & 21.51 \\
\hline TD & 20 & 18.47 & 11.42 & 31.39 & 20.05 & 35.59 & 13.40 \\
\hline OP & 20 & 12.71 & 4.70 & 17.02 & 9.80 & 17.48 & 9.05 \\
\hline $\mathrm{EF}$ & 20 & 14.00 & 5.53 & 31.09 & 22.24 & 39.25 & 25.66 \\
\hline FR & 20 & 10.94 & 10.31 & 18.13 & 12.95 & 14.52 & 8.98 \\
\hline WWL & 20 & 17.66 & 10.54 & 34.18 & 23.33 & 39.42 & 20.27 \\
\hline
\end{tabular}

MD: Mental Demand, PD: Physical Demand, TD: Temporal Demand, OP: Own Performance, EF: Effort, FR: Frustration, WWL: Weighted Workload

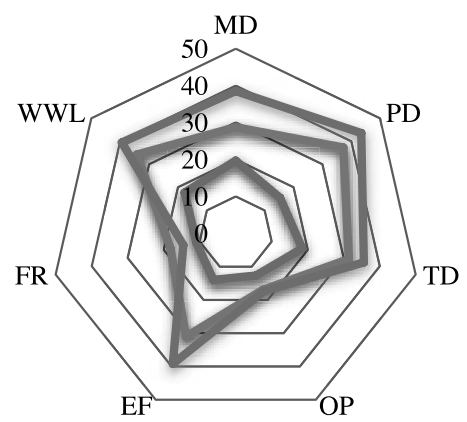

Fig. 2. Classification of NASA-TLX mean scores of ageing drivers between situation complexity.

A mixed model repeated measures ANOVA test was conducted to compare WWL scores on the NASA-TLX in different situation complexities. This analysis used a $2 \times 3$ repeated measures ANOVA (two levels: male vs. female) as between-subjects factor and situation complexity (three levels: simple situation, moderately complex situation, and very complex situation). The results of homogeneity tests of variances were analyzed, indicating that the variances among the groups were homogenous. Table 3 presents the results of repeated measures ANOVA test. The repeated measures ANOVA test revealed a significant main effect of situation complexity on all ageing drivers' subjective workload. The results showed that there was a significant effect of driving situation complexity on the ageing drivers' subjective workload ratings.

Table 3. Repeated measures ANOVA presents a significant main effect of situation complexity on ageing drivers' overall weighted workload of NASA-TLX.

\begin{tabular}{llcccc}
\hline Scale & Factor $(\mathbf{s})$ & df & F & p value & $\boldsymbol{\eta} 2$ \\
\hline \multirow{2}{*}{ WWL } & Situation Complexity & 2.00 & 14.66 & $\mathrm{p}<0.001^{* *}$ & 0.449 \\
& Gender & 1.00 & 0.32 & 0.579 & 0.017 \\
& Situation Complexity * Gender & 2.00 & 1.20 & 0.313 & 0.062 \\
\hline
\end{tabular}

**Significant at $p<0.01 ;$ WWL: Weighted Workload. 
Post hoc test (Bonferroni) was used for the overall weighted workload, which indicated that the mean weighted workload in simple situation was significantly different from the moderately complex situation $(\mathrm{p}=0.006)$ and very complex situation $(\mathrm{p}<0.001)$. On the other hand, no significant gender factor was found in its interaction with situation complexity on the NASA-TLX scales. The results showed no significant difference between male and female drivers' ratings.

\section{(2) EEG fluctuations on different situation complexity}

Table 4 and Table 5 report the results of $2 \times 3 \times 3$ repeated measures ANOVA with gender (male vs. female) as between-subjects factor and with situation complexity (three levels: simple situation, moderately complex situation, and very complex situation) and time on task (ToT) (S1 to S3) as within-subjects factors for EEG frequency bands of ageing drivers. For the time on task, the average time taken to complete each task was approximately 10 minutes for each participant. Only main driving state's EEG recordings were used for analysis, thus, data was analysed for 9 minutes of driving task (divided into three subminutes).

For $\mathrm{RP} \theta$ of channel $\mathrm{F}_{Z} \mathrm{P}_{Z}$, there was a significant effect of situation complexity $(p<0.001)$. Post hoc comparisons using the Bonferroni test indicated that the mean RP $\theta$ for very complex situation $(M=16.21, S E=0.89)$ was significantly different from simple situation $(M=19.63, S E=0.98), p=0.012$ and from moderately complex situation $(M=19.73, S E=1.05), p=0.002$. Overall, there was a significant difference between male $(M=24.24, S E=1.16)$ and female $(M=12.81, S E=1.16), p<0.001$.

Table 4. Electroencephalography RP $\theta$ results of ageing male vs. female drivers using 2 × 3 × 3 repeated measures ANOVA.

\begin{tabular}{|c|c|c|c|c|c|}
\hline $\begin{array}{l}\text { Channel } \\
\text { location }\end{array}$ & Factor (s) & df & $\mathbf{F}$ & p-value & $\eta 2$ \\
\hline \multirow{7}{*}{$\mathrm{F}_{\mathrm{Z}} \mathrm{P}_{\mathrm{Z}}$} & Situation Complexity & 2.00 & 9.73 & $\mathrm{p}<0.001 * *$ & 0.351 \\
\hline & Situation Complexity * Gender & 2.00 & 2.23 & 0.122 & 0.110 \\
\hline & Tot & 1.45 & 1.20 & 0.305 & 0.062 \\
\hline & Tot $*$ Gender & 1.45 & 2.62 & 0.106 & 0.127 \\
\hline & Situation Complexity $*$ Tot & 2.63 & 2.27 & 0.100 & 0.112 \\
\hline & Situation Complexity $*$ Tot $*$ Gender & 2.63 & 0.71 & 0.534 & 0.038 \\
\hline & Gender & 1.00 & 48.53 & $\mathrm{p}<0.001 * *$ & 0.729 \\
\hline \multirow{7}{*}{$\mathrm{O}_{1} \mathrm{O}_{2}$} & Situation Complexity & 1.50 & 3.41 & 0.060 & 0.159 \\
\hline & Situation Complexity * Gender & 1.50 & 2.81 & 0.091 & 0.135 \\
\hline & Tot & 1.50 & 0.11 & 0.841 & 0.006 \\
\hline & Tot $*$ Gender & 1.50 & 5.86 & $0.013^{*}$ & 0.246 \\
\hline & Situation Complexity * Tot & 4.00 & 1.74 & 0.150 & 0.088 \\
\hline & Situation Complexity * Tot $*$ Gender & 4.00 & 1.35 & 0.261 & 0.070 \\
\hline & Gender & 1.00 & 13.14 & $0.002 * *$ & 0.422 \\
\hline
\end{tabular}

*. Significant at the 0.05 level (2-tailed); **. Significant at the 0.01 level (2-tailed).

For RP $\theta$ of channel $\mathrm{O}_{1} \mathrm{O}_{2}$, there was a significant effect on the interaction between ToT and gender $(p=0.013)$. Post hoc Bonferroni test indicated that in ToT S1, the mean RP $\theta$ for males $(M=19.91, S E=1.32)$ was significantly different from females $(M=11.43, S E=1.32), p<0.001$. Meanwhile, in ToT S2, the mean RP $\theta$ for males $(M=19.11$, 
$S E=1.44)$ was significantly different from females $(M=12.59, S D=1.44), p=0.005$. Next, in ToT S3, the mean $\mathrm{RP} \theta$ for males $(M=18.56, S E=1.40)$ was significantly different from females $(M=12.84, S E=1.40), p=0.010$. Overall, there was a significant difference between males $(M=19.19, S E=1.35)$ and females $(M=12.29, S E=1.65)$, $p=0.002$.

For $\mathrm{RP} \alpha$ of channel $\mathrm{F}_{\mathrm{Z}} \mathrm{P}_{\mathrm{Z}}$, there was a significant effect on the interaction between situation complexity and gender $(p=0.034)$. The Bonferroni post hoc test indicated that for females, $\mathrm{RP} \alpha$ for simple situation $(M=9.81, S E=1.35)$ was significantly different from very complex situation $(M=6.22, S E=1.40), p=0.032$. There was also a significant effect on the interaction between situation complexity and ToT $(p=0.013)$. The Bonferroni post hoc test indicated that for ToT S1, RP $\alpha$ for moderately complex situation $(M=11.65, S E=0.79)$ was significantly different from very complex situation $(M=9.62, S E=0.79), p=0.005$. Meanwhile, it was also found that there was overall a significant difference between males $(M=14.28, S E=1.16)$ and females $(M=8.13, S E=1.16), p=0.001$.

For $\mathrm{RP} \alpha$ of channel $\mathrm{O}_{1} \mathrm{O}_{2}$, there was a significant effect of situation complexity ( $\left.p=0.023\right)$. Post hoc comparisons using the Bonferroni test indicated that $\mathrm{RP} \alpha$ for moderately complex situation $(M=10.48, S E=0.89)$ was significantly different from very complex situation $(M=8.63, S E=0.61), p=0.036$.

Table 5. Electroencephalography RP $\alpha$ results of ageing male vs. female drivers using 2 × 3 × 3 repeated measures ANOVA.

\begin{tabular}{llcccc}
\hline $\begin{array}{l}\text { Channel } \\
\text { location }\end{array}$ & Factor (s) & df & F & p-value & $\eta \mathbf{2}$ \\
\hline \multirow{3}{*}{$\mathrm{F}_{\mathrm{Z}} \mathrm{P}_{\mathrm{Z}}$} & Situation Complexity & 2.00 & 2.67 & 0.083 & 0.129 \\
& Situation Complexity * Gender & 2.00 & 3.71 & $0.034 *$ & 0.171 \\
& Tot & 2.00 & 1.78 & 0.183 & 0.090 \\
& Tot * Gender & 2.00 & 2.43 & 0.103 & 0.119 \\
& Situation Complexity * Tot & 4.00 & 3.44 & $0.013 *$ & 0.160 \\
& Situation Complexity * Tot * Gender & 4.00 & 0.33 & 0.860 & 0.018 \\
& Gender & 1.00 & 14.13 & $0.001 * *$ & 0.440 \\
\hline \multirow{3}{*}{$\mathrm{O}_{1} \mathrm{O}_{2}$} & Situation Complexity & 2.00 & 4.17 & $0.023 *$ & 0.188 \\
& Situation Complexity * Gender & 2.00 & 1.48 & 0.241 & 0.076 \\
& Tot & 2.00 & 0.06 & 0.942 & 0.003 \\
& Tot $*$ Gender & 2.00 & 1.44 & 0.250 & 0.074 \\
& Situation Complexity * Tot & 4.00 & 1.93 & 0.114 & 0.097 \\
& Situation Complexity * Tot * Gender & 4.00 & 0.74 & 0.568 & 0.039 \\
& Gender & 1.00 & 1.68 & 0.211 & 0.085 \\
\hline
\end{tabular}

*. Significant at the 0.05 level (2-tailed); **. Significant at the 0.01 level (2-tailed).

\section{(3) Comparison of weighted workload of NASA-TLX and EEG frequencies between age groups}

An independent samples $t$-test was conducted to compare overall weighted workload ratings (Table 6) and mean EEG bands (Table 7 and 8 ) of the ageing drivers and control group in each situation complexity. It is evident that there was a significant difference in the scores for ageing drivers' weighted workload $(M=17.66, S D=10.54)$ and control group's weighted workload $(M=32.15, S D=16.28) ; t(28)=-2.953, p=0.006$ in simple situation. This showed that there was a significant different between overall weighted workload in highway driving between ageing and young 
drivers. There was no significant difference found on moderately complex situation and very complex situation. No significant difference was found in the RP $\theta$ and $\mathrm{RP} \alpha$ bands at all channel locations $(\mathrm{p}>0.05)$.

Table 6. Independent samples $t$-test result comparing between ageing drivers and control group.

\begin{tabular}{|c|c|c|c|c|c|c|c|}
\hline \multirow{2}{*}{$\begin{array}{l}\text { Situation } \\
\text { Complexity }\end{array}$} & \multicolumn{3}{|c|}{ Ageing } & \multicolumn{2}{|c|}{ Control } & \multirow{2}{*}{ t-value } & \multirow{2}{*}{ p-value } \\
\hline & Scale & Mean & SD & Mean & SD & & \\
\hline SS & & 17.66 & 10.54 & 32.15 & 16.28 & -2.953 & $0.006^{* *}$ \\
\hline MCS & WWL & 34.18 & 23.33 & 43.57 & 19.80 & -1.089 & 0.285 \\
\hline VCS & & 39.42 & 20.27 & 53.38 & 14.14 & -1.946 & 0.062 \\
\hline
\end{tabular}

*Significant at $p<0.05 ; * *$ Significant at $p<0.01 ;$ WWL: Weighted Workload

Table 7. Electroencephalography RP $\theta$ band results of ageing vs. control group drivers.

\begin{tabular}{|c|c|c|c|c|c|c|c|}
\hline $\begin{array}{l}\text { Channel } \\
\text { location }\end{array}$ & $\begin{array}{l}\text { Situation } \\
\text { complexity }\end{array}$ & $\begin{array}{l}\text { Age } \\
\text { group }\end{array}$ & $\mathbf{N}$ & Mean & SD & t-value & p-value \\
\hline \multirow{6}{*}{$\mathrm{F}_{\mathrm{Z}} \mathrm{P}_{\mathrm{Z}}$} & \multirow[b]{2}{*}{ SS } & Ageing & 20 & 19.60 & 6.82 & \multirow[b]{2}{*}{-0.137} & \multirow[b]{2}{*}{0.892} \\
\hline & & Control & 10 & 19.95 & 6.10 & & \\
\hline & & Ageing & 20 & 19.73 & 6.98 & \multirow{2}{*}{-0.770} & \multirow{2}{*}{0.448} \\
\hline & ה IVIT & Control & 10 & 21.81 & 6.88 & & \\
\hline & \multirow{2}{*}{ VCS } & Ageing & 20 & 16.21 & 8.00 & \multirow{2}{*}{-0.307} & \multirow{2}{*}{0.761} \\
\hline & & Control & 10 & 17.12 & 6.88 & & \\
\hline \multirow{6}{*}{$\mathrm{O}_{1} \mathrm{O}_{2}$} & \multirow{2}{*}{ SS } & Ageing & 20 & 15.45 & 5.59 & \multirow{2}{*}{0.344} & \multirow{2}{*}{0.733} \\
\hline & & Control & 10 & 14.58 & 8.09 & & \\
\hline & \multirow[b]{2}{*}{ MCS } & Ageing & 20 & 17.04 & 6.28 & \multirow[b]{2}{*}{1.150} & \multirow[b]{2}{*}{0.260} \\
\hline & & Control & 10 & 14.28 & 6.06 & & \\
\hline & \multirow{2}{*}{ VCS } & Ageing & 20 & 14.68 & 6.06 & \multirow{2}{*}{0.994} & \multirow{2}{*}{0.329} \\
\hline & & Control & 10 & 12.51 & 4.66 & & \\
\hline
\end{tabular}


Table 8. Electroencephalography RP $\alpha$ band results of ageing vs. control group drivers.

\begin{tabular}{|c|c|c|c|c|c|c|c|}
\hline $\begin{array}{l}\text { Channel } \\
\text { location }\end{array}$ & $\begin{array}{l}\text { Situation } \\
\text { complexity }\end{array}$ & $\begin{array}{l}\text { Age } \\
\text { group }\end{array}$ & $\mathbf{N}$ & Mean & SD & t-value & p-value \\
\hline \multirow{6}{*}{$\mathrm{F}_{\mathrm{Z}} \mathrm{P}_{\mathrm{Z}}$} & \multirow{2}{*}{ SS } & Ageing & 20 & 11.81 & 4.66 & \multirow{2}{*}{-0.25} & \multirow{2}{*}{0.805} \\
\hline & & Control & 10 & 12.23 & 3.39 & & \\
\hline & \multirow{2}{*}{ MCS } & Ageing & 20 & 11.50 & 4.75 & \multirow{2}{*}{-1.688} & \multirow{2}{*}{0.103} \\
\hline & & Control & 10 & 14.75 & 5.41 & & \\
\hline & \multirow{2}{*}{ VCS } & Ageing & 20 & 10.24 & 5.98 & \multirow{2}{*}{-0.727} & \multirow{2}{*}{0.473} \\
\hline & & Control & 10 & 11.83 & 4.90 & & \\
\hline \multirow{6}{*}{$\mathrm{O}_{1} \mathrm{O}_{2}$} & \multirow{2}{*}{ SS } & Ageing & 20 & 9.45 & 3.95 & \multirow{2}{*}{-0.387} & \multirow{2}{*}{0.705} \\
\hline & & Control & 10 & 10.28 & 6.13 & & \\
\hline & \multirow{2}{*}{ MCS } & Ageing & 20 & 10.47 & 3.89 & \multirow{2}{*}{-0.234} & \multirow{2}{*}{-0.234} \\
\hline & & Control & 10 & 10.98 & 6.31 & & \\
\hline & \multirow{2}{*}{ VCS } & Ageing & 20 & 8.60 & 3.05 & \multirow{2}{*}{-1.508} & \multirow{2}{*}{0.143} \\
\hline & & Control & 10 & 10.92 & 5.40 & & \\
\hline
\end{tabular}

\section{DISCUSSION}

\section{Subjective measurements based on NASA-TLX}

In this study, situation complexity significantly affected almost overall weighted workload of the ageing drivers' NASA-TLX scores. This finding is consistent with previous studies (Arien et al., 2013; Patten et al., 2006; Törnros \& Bolling, 2006; Jahn et al., 2005; Verwey, 2000), which found differences in the subjective ratings based on the difficulty of the task assigned. Focusing on the ageing drivers' ratings, the mean physical demand score was the highest compared to others in rural and city driving. As expected, traffic density required a higher physical effort. Meanwhile, the results revealed that the mean physical demand ratings in rural and city areas were $83 \%$ and $95 \%$ in difference, respectively, as compared to those in highway roads. The results also indicated that the physical demand was more than doubled as the driving situation shifted from simple situation to moderately complex and very complex situations. This finding is consistent with Teh et al. (Teh et al., 2014), where their results revealed a significantly higher physical demand in medium and high traffic complexities compared to that in low traffic complexity. They also highlighted that there was an increasing linear trend in workload with an increasing traffic density. Parallel to the findings by Hopkin and Morris (2010), the traffic rating on physical demand in this study might be due to the effort and requirements to control the vehicle on the roads with more curves.

Interestingly, mental demand was rated the highest in highway driving (i.e., simple situation) compared to the scales of other scores. The results indicated that this type of road requires more mental effort to maintain a safe driving task in a monotonous route. However, comparing the situation complexity in this study, the highest mental demand was found in city driving ( $65 \%$ in difference from highway driving), where higher demand in terms of road and traffic densities occurred during the driving task execution. This result is in agreement with the findings of Fallahi et al. (Fallahi et al., 2016), where, in their study, mental demand was the most important in the proposed required task. They explained that the higher the average mental requirement is, the more the operator feels that his job is demanding. 
The overall weighted workload exhibited the highest score at city road, followed by rural road. The results in this study revealed that the mean weighted workload scores were $63 \%$ and $76 \%$ higher for moderately complex and very complex situations, respectively, compared to simple situation. These results confirmed that city and rural roads give higher loads of subjective perception of the ageing drivers who have the experience of functional impairment, resulting in an increased vulnerability to environmental challenges (Vysata et al., 2014). These results also indicated that the complexity of driving environment has an impact on the drivers' overall mental workload level. The overall workload of a task should not be too low or too high, as for most human operators, the performance indicator will be degraded when this situation happens (Hwang et al., 2007).

Overall, there was no significant difference between the ratings given by male and female drivers on the subjective workload in each task. This finding agrees with the previously reported results by Teh et al. (Teh et al., 2014), where they found that there was no significant effect of gender on all of the NASA-TLX scale scores in their driving experiments. These findings are contradictory with the findings by Seeker (Seeker, 2014), where he found that women have higher average mental workload than men. The contradiction might be due to different demographic characteristics of the participants involved in the study. Meanwhile, a comparison was made to see the difference between the control group and ageing drivers in terms of the weighted workload. The control group's weighted workload score was higher in all situation complexities, with significant difference found in simple situation. Although the young drivers were treated only as the comparison control group, they rated a higher score for the overall weighted workload compared to the ageing drivers. For simple situation, young drivers scored 58\% higher compared to the ageing drivers. This finding is consistent with Paxion et al. (2015), where it was found that lack of experience is a part of contributor to the increment of subjective workload.

\section{Electroencephalogram signals' fluctuation at different levels of situation complexity}

It is known that driving task would result in fluctuations of the driver's brain signal. In this study, the considered frequencies related to mental workload variations were the theta and alpha. For the EEG signals' fluctuation, the results showed significant effects of situation complexity. These findings are parallel to some of the previous studies (Maglione et al., 2014; Eoh et al., 2005). The main effect was found in RP $\theta$ and RP $\alpha$ of channel locations that indicate intention and motivation (i.e., $\mathrm{F}_{Z} \mathrm{P}_{Z}$ ), and occipital location (i.e., $\mathrm{O}_{1} \mathrm{O}_{2}$ ) that usually reflects visualization (Borghini et al., 2014). Both frequencies were found to be lower in the city compared to rural roads. These findings are in line with the concepts of theta and alpha activities, in which the power in this frequency band is related to sleepiness and information processing for the activities mentioned, respectively. In city driving, intention and visualization are highly needed by drivers, resulting in lower alpha (reflecting the increment of attentional demands) (Ryu \& Myung, 2005; Sterman et al., 1994) and lower theta (less sleepiness occurred) compared to other types of roads. Meanwhile, there was a significant effect on interaction between situation complexity and gender, in which further analysis indicated that for female, the RP $\alpha$ for simple situation was significantly higher than very complex situation. This finding indicated that there was an increment in information processing activity in very complex situation compared to the one in simple situation.

Inspecting the effects of time on task (ToT), interestingly, there was a significant effect on the interaction between situation complexity and ToT, where in the first three minutes of driving (S1), the RP $\alpha$ for moderately complex situation was significantly higher than that in very complex situation. This result indicated that at the earlier stage of the driving task, the ageing drivers had experienced a higher demand (higher amount of information processing activity) in city driving compared to rural driving. The result is consistent with the findings of previous studies, where they highlighted that the alpha power is sensitive to the changes in task load (Maglione et al., 2014; Lei \& Roetting, 2011). Furthermore, Li et al. (Li et al., 2017) found that the alpha power increased when the driver was sleepy in their driving experiment. Their finding is in parallel with the current study, where boredom might occur during rural road driving, thus resulting in attentional withdrawal (Wascher et al., 2016).

Analyzing the effect of gender on EEG band frequency, the results indicated that a significant effect of gender was found in most cases of RP $\theta$ and RP $\alpha$. Regardless the situation complexity and ToT, frequency bands were higher 
among male drivers compared to female drivers. Examining the significant interactions further, for channel $\mathrm{O}_{1} \mathrm{O}_{2}$, overall in each ToT, RP $\theta$ was higher among the male drivers. Lower RP $\theta$ was found among female drivers, indicating that less sleepiness occurred among female drivers compared to male drivers during the time on task (Sandberg et al., 2011; Eoh et al., 2005; Otmani et al., 2005). Since the channel locations indicate the visual activity of the task, the female drivers showed more engagement and effort to keep the visualization on monitoring driving conflicts during the task. These findings are contradictory with the findings by Kim et al. (Kim et al., 2014) and Larue et al. (Larue et al., 2011), where no significant differences between male and female drivers were found in most cases of their studies in quantifying the driving workload on a real road and a simulated one. The contradiction might be due to the design of the study, such as the age of the participants, time of the experiment, and type of task assigned to the participants. Significant interaction between situation complexity and gender was found on $\mathrm{RP} \alpha$ of channel $\mathrm{F}_{\mathrm{Z}} \mathrm{P}_{\mathrm{Z}}$, where further analysis indicated that the alpha frequency of the ageing female drivers was significantly higher in simple situation compared to very complex situation. This finding also highlighted that highway driving requires lower information processing activity compared to city driving. The result reflected that highway road requires less mental effort, thus resulting in a higher potential of sleepiness, especially in a driving task on a monotonous route. This finding supports the fact that improving highway safety is a high priority for highway authorities (Abdulsalam et al., 2015). The EEG frequencies were compared between the ageing drivers and the control group. It was found that there were no significant differences in mean RP $\theta$ and RPa.

\section{CONCLUSION}

The research highlighted that the empirical method using multichannel EEG relative power bands and NASA-TLX rating had accurately estimated the mental workload of ageing drivers. The EEG relative power bands showed that there was a significant effect of situation complexity mainly on RP $\theta$ and $R P \alpha$ of channel locations that indicate intention and motivation, with occipital location that reflects visualization. Both frequencies were found to be significantly lower in city road compared to other roads indicating lower levels of sleepiness and drowsiness respectively. In city driving, intention and visualization were highly required by the drivers resulting in lower alpha (increment of attentional demands) and lower theta (occurrence of less sleepiness) compared to other types of roads. No significant difference was observed between male and female drivers' ratings of the subjective workload in each task, whereas significant gender effects were found in most cases of RP $\theta$ and RP $\alpha$. These findings reflected on the perception that the physical demand more than doubles as the driving situation shifts from simple situation to moderately complex and very complex situations, where higher traffic density requires higher physical effort. The findings would be beneficial as an important guideline for car engineers and engineering designers as well as local authority and policy makers in designing better driving environment for ageing drivers.

\section{REFERENCE}

Abdulsalam, A.J., Hassan, Y., \& Abd El Halim, A.O. 2015. The effect of automated speed cameras on fatal traffic collisions in Kuwait. J. Eng. Res. 3(4): 17-29.

Amodio, P., Orsato, R., Marchetti, P., Schiff, S., Poci, C., Angeli, P., \& Toffolo, G.M. 2009. Electroencephalographic analysis for the assessment of hepatic encephalopathy: comparison of non-parametric and parametric spectral estimation techniques. Neurophysiol Clin, 39(2): 107-115.

Andreassi, J.L. 2000. Psychophysiology: Human Behavior and Physiological Response. New Jersey London: Lawrence Erlbaum Associates.

Arien, C., Jongen, E.M., Brijs, K., Brijs, T., Daniels, S., \& Wets, G. 2013. A simulator study on the impact of traffic calming measures in urban areas on driving behavior and workload. Accid Anal Prev, 61: 43-53.

Arokiasamy, J.T. 1999. Malaysia's ageing population: challenges in the new millennium. Med J Malaysia, 54(4): $429-432$.

BIOPAC Systems Inc. 2016. MP System Hardware Guide. Retrieved from www.biopac.com

Böcker, L., van Amen, P., \& Helbich, M. 2017. Elderly travel frequencies and transport mode choices in Greater Rotterdam, the 
Netherlands. Transportation, 44(4): 831-852.

Borghini, G., Astolfi, L., Vecchiato, G., Mattia, D., \& Babiloni, F. 2014. Measuring neurophysiological signals in aircraft pilots and car drivers for the assessment of mental workload, fatigue and drowsiness. Neurosci Biobehav Rev, 44: 58-75.

Chen, D., \& Vertegaal, R. 2004. Using mental load for managing interruptions in Physiologically Attentive User Interfaces. Paper presented at the Conference on Human Factors in Computing Systems, Vienna, Austria.

Cheung, I., \& McCartt, A.T. 2011. Declines in fatal crashes of older drivers: changes in crash risk and survivability. Accid Anal Prev, 43(3): 666-674.

De Waard, D. 1996. The measurement of drivers' mental workload., University of Groningen, Haren, The Netherlands.

Doufesh, H., Ibrahim, F., Ismail, N.A., \& Wan Ahmad, W.A. 2014. Effect of Muslim prayer(Salat) on alpha electroencephalography and its relationship with autonomic nervous system activity. J Altern Complement Med, 20(7): 558-562.

Eoh, H.J., Chung, M., \& Kim, S.-H. 2005. Electroencephalographic study of drowsiness in simulated driving with sleep deprivation. International Journal of Industrial Ergonomics, 35: 307-320.

Fallahi, M., Motamedzade, M., Heidarimoghadam, R., Soltanian, A.R., \& Miyake, S. 2016. Effects of mental workload on physiological and subjective responses during traffic density monitoring: A field study. Appl Ergon, 52: 95-103.

Hart, S.G., \& Staveland, L.E. 1988. Development of NASA-TLX (Task Load Index): Results of Empirical and Theoretical Research. Advances in Psychology, 52: 139-183.

Hopkin, J., \& Morris, B. 2010. Older Drivers -Safe or Unsafe? . Retrieved from

HQs Civil Aviation Authority. 2009. Flight Standards Directorate Concept of Mental Workload. Retrieved from Pakistan.:

Hwang, S.L., Yau, Y.J., Lin, Y.T., Chen, J.H., Huang, T.H., Yenn, T.C., \& Hsu, C.C. 2007. A Mental Workload Predicator Model for the Design of Pre Alarm Systems. In D. Harris (Ed.), Engineering Psychology and Cognitive Ergonomics: 7th International Conference, EPCE 2007, Held as Part of HCI International 2007, Beijing, China, July 22-27, 2007. Proceedings (pp. 316-323). Berlin, Heidelberg: Springer Berlin Heidelberg.

Jahn, G., Oehme, A., Krems, J.F., \& Gelau, C. 2005. Peripheral detection as a workload measure in driving: Effects of traffic complexity and route guidance system use in a driving study. Transportation Research Part F: Traffic Psychology and Behaviour, 8(3), 255-275.

Kim, H.S., Hwang, Y., Yoon, D., Choi, W., \& Park, C.H. 2014. Driver Workload Characteristics Analysis Using EEG Data From an Urban Road. IEEE Transactions on Intelligent Transportation Systems, 15(4): 1844-1849.

Larue, G.S., Rakotonirainy, A., \& Pettitt, A.N. 2011. Driving performance impairments due to hypovigilance on monotonous roads. Accid Anal Prev, 43(6), 2037-2046.

Lean, Y., \& Shan, F. 2012. Brief review on physiological and biochemical evaluations of human mental workload. Hum. Factor. Ergon. Manuf., 22(3): 177-187.

Lei, S., \& Roetting, M. 2011. Influence of Task Combination on EEG Spectrum Modulation for Driver Workload Estimation. Human Factors, 53(2): 168-179.

Leung, A.W. 2006. Neurophysiological Correlates of Performance and Fatigue in Study of Mental Workload. (Doctor of Philosophy), The Hong Kong Polytechnic University, Hong Kong.

Li, F., Zhou, J., \& Lyu, N. 2017. Driving performance characteristics affected by road edge rate marking on bridge section. Paper presented at the 2017 4th International Conference on Transportation Information and Safety (ICTIS).

Maglione, A., Borghini, G., Arico, P., Borgia, F., Graziani, I., Colosimo, A., Babiloni, F. 2014. Evaluation of the workload and drowsiness during car driving by using high resolution EEG activity and neurophysiologic indices. Conf Proc IEEE Eng Med Biol Soc, 2014: 6238-6241.

Miyake, S. 2001. Multivariate workload evaluation combining physiological and subjective measures. Int J Psychophysiol, 40(3): 233-238.

Otmani, S., Roge, J., \& Muzet, A. 2005. Sleepiness in professional drivers: effect of age and time of day. Accid Anal Prev, 37(5): 930-937. 
Patten, C.J.D., Kircher, A., Östlund, J., Nilsson, L., \& Svenson, O. 2006. Driver experience and cognitive workload in different traffic environments. Accident Analysis \& Prevention, 38(5): 887-894.

Paxion, J., Galy, E., \& Berthelon, C. 2014. Mental workload and driving. Frontiers in Psychology, 5: 1344.

Paxion, J., Galy, E., \& Berthelon, C. 2015. Overload depending on driving experience and situation complexity: Which strategies faced with a pedestrian crossing? Appl Ergon, 51: 343-349.

Reid, G.B., \& Nygren, T.E. 1988. The Subjective Workload Assessment Technique: A Scaling Procedure for Measuring Mental Workload. Advances in Psychology, 52: 185-218.

Ryu, K., \& Myung, R. 2005. Evaluation of mental workload with a combined measure based on physiological indices during a dual task of tracking and mental arithmetic. International Journal of Industrial Ergonomics, 35(11): 991-1009.

Sandberg, D., Anund, A., Fors, C., Kecklund, G., Karlsson, J.G., Wahde, M., \& Åkerstedt, T. 2011. The Characteristics of Sleepiness During Real Driving at Night-A Study of Driving Performance, Physiology and Subjective Experience. Sleep, 34(10): 1317-1325.

Seeker, A. 2014. Using Outputs of NASA-TLX for Building a Mental Workload Expert System. Gazi University Journal of Science, 27(4): 1131-1142.

Son, J., Park, M., \& Park, B.B. 2015. The effect of age, gender and roadway environment on the acceptance and effectiveness of Advanced Driver Assistance Systems. Transportation Research Part F: Traffic Psychology and Behaviour, 31: 12-24.

Sterman, M.B., Mann, C.A., Kaiser, D.A., \& Suyenobu, B.Y. 1994. Multiband topographic EEG analysis of a simulated visuomotor aviation task. Int J Psychophysiol, 16(1), 49-56.

Teh, E., Jamson, S., Carsten, O., \& Jamson, H. 2014. Temporal fluctuations in driving demand: The effect of traffic complexity on subjective measures of workload and driving performance. Transportation Research Part F: Traffic Psychology and Behaviour, 22: 207-217.

Törnros, J., \& Bolling, A. 2006. Mobile phone use - effects of conversation on mental workload and driving speed in rural and urban environments. Transportation Research Part F: Traffic Psychology and Behaviour, 9(4): 298-306.

Tsang, P.S., \& Velazquez, V.L. 1996. Diagnosticity and multidimensional subjective workload ratings. Ergonomics, 39(3): 358-381.

Verwey, W.B. 2000. Effects of road situation and age on secondary task measures. On-line driver workload estimation. Ergonomics, $43(2)$.

Vysata, O., Kukal, J., Prochazka, A., Pazdera, L., Simko, J., \& Valis, M. 2014. Age-related changes in EEG coherence. Neurologia i Neurochirurgia Polska, 48(1): 35-38.

Wascher, E., Getzmann, S., \& Karthaus, M. 2016. Driver state examination--Treading new paths. Accid Anal Prev, 91: 157-165.

World Health Organization. (2018). Ageing and health.

Xie, B., \& Salvendy, G. 2000. Review and reappraisal of modelling and predicting mental workload in single- and multi-task environments. Work \& Stress, 14(1): 74-99.

Zadry, H.R., Dawal, S.Z.M., \& Taha, Z. 2010. Upper Limb Muscle and Brain Activity in Light Assembly Task on Different Load Levels. AIP Conference Proceedings, 1285(1): 396-408.

Zadry, H.R., Dawal, S.Z.M., \& Taha, Z. 2011. The relation between upper limb muscle and brain activity in two precision levels of repetitive light tasks. Int J Occup Saf Ergon, 17(4): 373-384. 